\title{
Predictive Value of Women's Weight Trajectories in Determining Familial Cardiovascular Disorders: A Family Based Longitudinal Study
}

Parisa Naseri

Shaheed Beheshti University of Medical Sciences

Parisa Amiri ( $\square$ amiri@endocrine.ac.ir)

Shahid Beheshti University of Medical Sciences: Shaheed Beheshti University of Medical Sciences

Amirali Zareie-Shabkhaneh

Tehran University of Medical Sciences

Fereidoun Azizi

shahid Beheshti university of Medical sciences

Original investigation

Keywords: Cardiovascular risk factors, BMI trajectory patterns, family environment, latent class growth analysis

Posted Date: November 5th, 2020

DOI: https://doi.org/10.21203/rs.3.rs-101452/v1

License: (c) (i) This work is licensed under a Creative Commons Attribution 4.0 International License. Read Full License 


\section{Abstract}

Background: Considering dynamic nature of body mass index (BMI) in women, is crucial to determine cardiovascular risks in both individual and familial levels. This study aimed to investigate the life-course trajectory pattern of women's BMI and its association with cardiovascular risk factors in them and their family members.

Methods: Based on the Tehran Lipid and Glucose Study (TLGS), a total of 1356 mothers with 2976 children (51.8\% girls) aged $\leq 18$ years at baseline were recruited in the current analysis and followed up for an average period of 15 years. Cardiovascular risk factors, including hypertension (HTN), dyslipidemia, diabetes mellitus (DM), and obesity were considered as outcome variables. Latent growth curve modelling (LGCM) was applied to determine women's BMI trajectories; then, logistic regression was used to investigate the associations between trajectory patterns of women and cardiovascular risk factors among whole family members.

Results: Women were classified into three trajectory groups labeled as normal, overweight, and obese. Compared to women's in the normal trajectory group, those in the overweight and obesity trajectory groups had higher odds ratios for HTN, DM, and dyslipidemia $(p<0.05)$. In the final model, men with obese spouses showed a higher rate of HTN 1.54 (95\% Cl: 1.05-2.25) and DM 1.55; (95\% Cl: 1.00-2.44). The odds of men's obesity were higher in their obese spouses compared to normal weight ones, and the odds ratios were (OR=1.70; $95 \% \mathrm{Cl}: 1.10-2.62)$. Offspring of obese and overweight mothers were more likely to be obese than those whose mothers were normal weight. The odds ratios were $(\mathrm{OR}=2.39 ; 95 \% \mathrm{Cl}: 1.67-3.44)$ and $(\mathrm{OR}=4.81 ; 95 \% \mathrm{Cl}: 3.16-7.34)$ respectively. The corresponding value for dyslipidemia in offspring with obese mothers were 1.39 (95\% Cl: 1.00-1.94).

Conclusions: Our results showed that women's weight status over time, play a critical role in determining cardiovascular risk, not only in them but also in their family members. The current results emphasized paying more attention to women with excessive weight to promote familial cardiovascular health in the communities.

\section{Background}

Cardiovascular diseases (CVDs) are the leading causes of death in developed and developing countries $(1,2)$. The worldwide mortality rate from CDVs showed a considerable rising trend, up to $15 \%$, between 2006 to 2016 (1). According to existing evidence, CVDs are also lead to $12 \%$ of global disability during life years (3). In Iran, around 50\% of deaths are caused by CVDs (4). Obesity, diabetes mellitus (DM) (5), dyslipidemia, and hypertension (HTN) (6) as welldocumented risk factors for CVDs could significantly threaten individuals' health. It is predicted that by 2030 , a total of 2.16 and 1.12 billion individuals will be overweight and obese, respectively, and $30 \%$ and $9.3 \%$ of adults worldwide have hypertension and DM, respectively (7-9). In Iran, the rate of excessive weight is considerably high; recent data showed $12.8-76.4$ and $2.4-35.4 \%$ of Iranian adults suffer from overweight and obesity (8). Moreover, the prevalence of hypertension and DM were $29.9 \%$ and $9.94 \%$, respectively $(10,11)$.

The familial environment has been proposed as an important contributor to CVD risk factors, including obesity (12). Socioeconomic status (SES) and parental modelling of eating behaviors are examples of familial factors that have been related to developing CVD risk factors (13-15). A growing number of studies showed the association between parental obesity and their offsprings' weight status (16-18). Studies indicated parental body mass index (BMI), particularly mother's BMI, as the main determinant of excessive weight gain in children during the life span from childhood to adulthood. It is significantly contributed to other cardio-metabolic risk factors (19). However, the relationships between mothers' weight status and metabolic complications in offspring are under debate. This issue of whether offspring with obese mothers are at higher risk for cardiometabolic impairment needs to be determined (20).

In addition to offspring, weight status in women may affect their spouses' cardiovascular risk factors. A study assessed the reciprocal effects of couple obesity and indicated that excessive weight in wives increased the risk of type 2 diabetes in their husbands; however, this effect was not observed in women (21). This finding indicates the potential role of women's weight status in association with their husbands' cardiovascular risk factors. The spousal concordance, defined as consistency in health status between a husband and a wife, has been well known (22). Several cross-sectional studies on spousal concordance have been conducted in chronic diseases, including hypertension (23, 24), cardiovascular diseases (25-27), cancers (28), and type 2 diabetes (29), which may be explained by the shared environment (22). In Iran, the spousal concordance for type 2 diabetes and hypertension has been previously shown in cross-sectional studies $(30,31)$.

In terms of weight status, several studies investigated the cross-sectional association between BMI and CVD risk factors (32). Due to the changes in BMI patterns in recent years, the growth trajectories have been used to assess the life-course prevention of CVDs. A few studies are available on the long-term lifecourse change of BMl; however, no findings are found on the cardiovascular risk factors associated with the life-long change of women's BMI in terms of familial association (33-38). In addition, one cannot extend these findings due to the different socio-environmental factors among populations. To the best of our knowledge, this is the first longitudinal study in the world which aimed to determine the life-course trajectory patterns of women's BMI and to identify which trajectory pattern was associated with a higher cardiovascular risk in whole family members as well as women's own cardiovascular risk factors.

\section{Methods}

\section{Study design and population}

This study used data from the Tehran Lipid and Glucose Study (TLGS), an ongoing population-based cohort with every-three-year measurements to determine the prevalence of non-communicable diseases (NCDs) risk factors in a representative sample of residents of district no.13 of Tehran. The first survey, including 15005 participants (women and men, aged $\geq 3$ years), was initiated in 1999-2001. Details of the TLGS have previously been published (39). 
For the present study, a total of 2556 couples were selected from the first phase and followed for 15 years (till phase 6); after the exclusion of 330 couples with reported widowhood or divorce, 2226 couples remained. Afterward, mothers with at least four missing measurements on BMI were excluded ( $n=870)$. The final analytic sample for latent class growth analysis (LCGA) comprises 1356 mothers with 2976 children ( $51.8 \%$ girls), aged $\leq 18$ years at baseline. Written informed consent was obtained from all participants. The study protocol was approved by the ethics committee of the Research Institute for Endocrine Sciences (RIES) of the Shahid Beheshti University of Medical Sciences.

\section{Measurements}

Trained interviewers collected data on age, sex, educational level, marital status, smoking status, physical activity, and medical and drug history using a pretested questionnaire. Blood pressure was recorded in a sitting position using a standard mercury sphygmomanometer with the cuff placed on the right arm. Two measurements were taken twice at the interval of 5 minutes each, and mean values were considered for systolic and diastolic blood pressure (SBP and DBP) (39). Blood glucose and lipid levels including Triglycerides (TGs) and High-density lipoprotein (HDL-C), Total cholesterol (TC), fasting plasma glucose (FPG), and 2-hour post-load plasma glucose (2 hour-PLPG) were measured using a morning blood sample which was obtained from participants in each phase at the TLGS research laboratory on the day of blood collection (39). Weight of individuals was measured using digital scales, in light clothing and without shoes and recorded to the nearest $100 \mathrm{~g}$. Height was measured using a tape meter. BMI was calculated as weight in kilograms divided by square of height in meters. Reliable and validated the Modifiable Activity Questionnaire (MAQ) was used to measure three forms of activities, including leisure time, job, and household activities in the past year based on MET-minutes/week (40).

\section{Definition of terms}

Hypertension was defined as mean SBP $\geq 140 \mathrm{~mm} \mathrm{Hg}$ or mean DBP $\geq 90 \mathrm{~mm} \mathrm{Hg}$ or taking antihypertensive drugs (41), and DM was defined as FPG $\geq$ $7 \mathrm{mmol} / \mathrm{L}$ or 2 hour-PLPG $\geq 11.1 \mathrm{mmol} / \mathrm{L}$ (42) or using glucose-lowering medications. Dyslipidemia was defined as TG $\geq 1.69 \mathrm{mmol} / \mathrm{L}$ or $\mathrm{HDL}-\mathrm{C}$ levels < $1.04 \mathrm{mmol} / \mathrm{L}$ in men and $<1.29 \mathrm{mmol} / \mathrm{L}$ in women or $\mathrm{TC} \geq 5.2 \mathrm{mmol} / \mathrm{L}$ or using lipid-lowering medications (43). A BMl equal to or more than $30 \mathrm{~kg} / \mathrm{m}^{2}$ in adults is defined as obesity (44). Education level was classified into three categories: primary, secondary, and higher. Smoking status was classified as a smoker (current smokers) and nonsmoker (past or never smokers). A person who smokes cigarettes or uses other tobacco products daily or occasionally was considered as current smoker.

\section{Statistical analysis}

Baseline characteristics of the mothers, fathers and their offspring were summarized as means \pm SD and frequencies (percentages) for continuous and categorical variables, respectively. Results were stratified based on mother trajectories. Continuous and categorical variables were compared between mother trajectories using the one-way ANOVA and the Chi-square tests.

LCGA is a semi-parametric technique used to identify distinct subgroups of individuals following a similar pattern of change over time on a given variable. In the current analysis, this approach is used to identify patterns of BMI, which determines mothers with similar behavioral trajectories (45). We applied the PROC TRAJ procedure extension for SAS to build group-based multi-trajectory models via a special application of finite mixture modelling. Model selection was made in two steps. In the first step, the number of trajectory groups was determined based on the Bayesian information criterion (BIC) and substantive significance (46). In the second step, we tested the various shapes of each latent class to identify the pattern of change over time (linear, quadratic, or cubic). In all analyses, the minimal class sizes of at least $5 \%$ of the sample were considered. The models' goodness of fit was assessed using the average posterior probability (APP) of group membership $\geq 70 \%$ and that the odds of correct classification (OCC) $\geq 5$ for each group and similarities between the estimated probability of the trajectory group and the proportion assigned to the group as suggested by Nagin (46). Following the identification of the trajectory groups, each group was assigned a label regarding their pattern of BMI during the follow-up phases.

We examined the associations of each lifetime BMI trajectory group with cardiometabolic risk factors by logistic regression models. BMI trajectory group as a predictor was included in models, and the normal group was considered as a reference category. The first model was unadjusted; the second model was adjusted for age, education, employment, and marital status, and the third model was further adjusted for smoking status and physical activity. Also, in assessing the association between mother's trajectory groups and her offspring, sex was also considered in all mentioned models. Statistical analyses were performed using SAS (version 9.4; SAS Institute Inc) and IBM SPSS Statistics version 22. $P<0.05$ was considered statistically significant.

\section{Results}

\section{BMI trajectory patterns}

BMI of women for each predicted trajectory group across follow-up measurements was presented in Fig. 1. The LCGM identified three trajectory groups for BMI in 1356 mothers. Based on the goodness of fit criteria in Table 1, although four and five trajectory groups were statistically appropriate, a three-trajectory group was the best fitting model according to our basis hypothesis. The BIC for this model was -18208.71 , and the APP ranged from 0.95 to 0.96 . The OCC was $33.69,26.70$, and 169.72 for the first to third groups, respectively, and $41.6 \%, 43.70 \%$, and $14.7 \%$ of the participants were grouped into class 1 , class 2 , and class 3 , respectively. The three patterns were labelled as class $1 /$ Normal, class $2 / O v e r w e i g h t$, class $3 /$ Obese. The normal trajectory pattern showed a steady normal BMI during baseline to the last follow-up assessments. The overweight trajectory group showed a higher BMI increase during the follow-up period, whereas the BMI level was always within the overweight range. The obese trajectory group was characterized by a steep rise in BMI over follow-ups, including those who were obese at baseline and remained in the same weight status in all follow-up measurements. Table 2 shows BMI changes in each group over the follow-up period. As expected, in all trajectory groups, BMI increases through the follow-up period. The highest and lowest mean BMI were about 39 and 24 at the fourth and baseline measurements, respectively. 
Table 1

Model fit characteristics for trajectory model analysis.

\begin{tabular}{|c|c|c|c|c|c|c|c|}
\hline Trajectory group & $\mathbf{N}$ & Estimated (SE) & $\begin{array}{l}\text { Assigned } \\
(\%)\end{array}$ & APP (\%) & occ & $\begin{array}{l}\text { BIC } \\
(n=7213)\end{array}$ & BIC $(n=1356)$ \\
\hline 2-group model & & & & & & -19288.23 & -19281.54 \\
\hline 1 & 972 & $71.62(1.37)$ & 71.68 & 0.98 & 22.79 & & \\
\hline 2 & 384 & $28.37(1.37)$ & 28.31 & 0.95 & 58.76 & & \\
\hline 3-group model & & & & & & -18218.73 & -18208.71 \\
\hline 1 & 566 & $41.55(1.56)$ & 41.74 & 0.96 & 33.69 & & \\
\hline 2 & 591 & $43.71(1.51)$ & 43.58 & 0.95 & 26.70 & & \\
\hline 3 & 199 & $14.73(1.06)$ & 14.67 & 0.96 & 169.72 & & \\
\hline 4-group model & & & & & & -17556.89 & -17543.52 \\
\hline 1 & 435 & $32.11(1.45)$ & 32.07 & 0.95 & 47.94 & & \\
\hline 2 & 578 & $42.46(1.50)$ & 42.62 & 0.95 & 25.75 & & \\
\hline 3 & 270 & $19.97(1.16)$ & 19.91 & 0.95 & 93.99 & & \\
\hline 4 & 73 & $5.45(0.65)$ & 5.38 & 0.97 & 657.81 & & \\
\hline 5-group model & & & & & & -17152.55 & -17135.83 \\
\hline 1 & 128 & $9.81(0.99)$ & 9.43 & 0.94 & 162.90 & & \\
\hline 2 & 467 & $33.84(1.46)$ & 34.43 & 0.93 & 25.44 & & \\
\hline 3 & 447 & $33.22(1.45)$ & 32.96 & 0.94 & 34.81 & & \\
\hline 4 & 246 & $18.04(1.10)$ & 18.14 & 0.95 & 104.09 & & \\
\hline 5 & 68 & $5.07(0.64)$ & 5.01 & 0.97 & 808.78 & & \\
\hline 6-group model & & & & & & -16941.10 & -16921.05 \\
\hline 1 & 126 & $9.43(0.93)$ & 9.29 & 0.94 & 160.90 & & \\
\hline 2 & 445 & $32.55(1.43)$ & 32.81 & 0.93 & 30.97 & & \\
\hline 3 & 440 & $32.20(1.43)$ & 32.44 & 0.93 & 30.02 & & \\
\hline 4 & 220 & $16.40(1.11)$ & 16.22 & 0.94 & 88.51 & & \\
\hline 5 & 87 & $6.51(0.73)$ & 6.41 & 0.93 & 218.31 & & \\
\hline 6 & 38 & $2.88(0.64)$ & 2.80 & 0.96 & 899.35 & & \\
\hline
\end{tabular}

Table 2

Women's BMI over follow-ups.

\begin{tabular}{|llll|}
\hline & \multicolumn{3}{|c|}{ Mean BMI } \\
\hline & Normal & Overweight & Obese \\
\hline Baseline & $24.19 \pm 2.50$ & $29.12 \pm 2.34$ & $34.66 \pm 3.14$ \\
\hline Follow-up 1 & $25.25 \pm 2.23$ & $30.35 \pm 2.16$ & $36.47 \pm 2.79$ \\
\hline Follow-up 2 & $25.59 \pm 2.12$ & $30.40 \pm 2.01$ & $36.87 \pm 3.39$ \\
\hline Follow-up 3 & $26.13 \pm 2.20$ & $31.21 \pm 2.22$ & $38.34 \pm 3.85$ \\
\hline Follow-up 4 & $26.42 \pm 2.21$ & $31.48 \pm 2.34$ & $38.80 \pm 3.58$ \\
\hline Follow-up 5 & $26.55 \pm 2.28$ & $31.60 \pm 2.40$ & $38.69 \pm 4.04$ \\
\hline
\end{tabular}

\section{Participants' characteristics based on the BMI trajectory groups in women}

The characteristics of all participants (women, Husband, and offspring) based on women's trajectories are shown in Table 3 . The fathers ranged in age from 57 to 61 years old, and the average age of mothers varied between 51 to 55 years old in different groups, and the corresponding values for their offspring ranged from 27 to 28 years old. Comparing men's characteristics in different women's BMI trajectory showed a significant statistical difference for all 
examined variables except for dyslipidemia and smoking. Furthermore, apart from employment status, all women's variables were significant among their BMI trajectory groups. In the last follow-up, compared to those in other BMI trajectory patterns, women in the obese trajectory group and their spouses were the oldest $(p<0.001)$, and most of them had a low level of education, were less physically active, and more smoker. In addition, hypertension and diabetes type 2 were more prevalent in steady obese mothers and their spouses. In terms of offspring, obesity, marital status, dyslipidemia, and age were statistically different among their mothers' BMI trajectory groups. Children whose mothers were in the steady obese trajectory group had the highest prevalence of obesity (31.9\%) and dyslipidemia (64.9\%).

Table 3. Descriptive statistics of whole family members across the trajectory pattern of women's BMI.

\begin{tabular}{|c|c|c|c|c|c|c|c|c|c|c|c|c|}
\hline & & Husband & & & & Women & & & & Offspring & & \\
\hline & Normal & Overweight & Obese & P-value & Normal & Overweight & Obese & P-value & Normal & Overweight & Obese & P-value \\
\hline$\overline{\text { Sex }}$ & & & & & & & & & & & & 0.31 \\
\hline Boy & & & & & & & & & $222(46.8)$ & $268(50.8)$ & $84(45.4)$ & \\
\hline Girl & & & & & & & & & $252(53.2)$ & $260(49.2)$ & $101(54.6)$ & \\
\hline $\begin{array}{l}\text { Age } \\
\text { Education }\end{array}$ & $57.15 \pm 7.75$ & $59.98 \pm 8.24$ & $61.51 \pm 8.73$ & $<0.001$ & $51.43 \pm 7.48$ & $54.79 \pm 7.75$ & $55.74 \pm 8.36$ & $<0.001$ & $27.35 \pm 4.61$ & $28.61=4.31$ & $28.79 \pm 3.89$ & $<0.001$ \\
\hline Primary & $61(15.2)$ & $93(22.9)$ & $35(23.6)$ & 0.001 & $70(15.5)$ & $127(28.1)$ & $59(41.3)$ & $<0.001$ & $1(0.2)$ & $2(0.4)$ & 0 & \\
\hline Secondary & $238(59.2)$ & $227(55.8)$ & $92(62.2)$ & & $323(71.3)$ & $273(60.4)$ & $76(53.1)$ & & $182(38.4)$ & $179(33.9)$ & $66(35.7)$ & \\
\hline Higher & $103(25.6)$ & $87(21.4)$ & $21(14.2)$ & & $60(13.2)$ & $52(11.5)$ & $8(5.6)$ & & $291(61.4)$ & $347(65.7)$ & $119(64.3)$ & \\
\hline Employment & & & & $<0.001$ & & & & 0.06 & & & & 0.30 \\
\hline Employed & $273(67.9)$ & $228(56)$ & $62(46.6)$ & & $39(8.6)$ & $32(7.1)$ & $4(2.8)$ & & $252(53.2)$ & $303(57.4)$ & $108(58.4)$ & \\
\hline Un-employed & $129(32.1)$ & $179(44)$ & $71(53.4)$ & & $414(91.4)$ & $420(92.9)$ & $139(97.2)$ & & $222(46.8)$ & $225(42.6)$ & $77(41.6)$ & \\
\hline $\begin{array}{l}\text { Physical activity } \\
\text { smoking }\end{array}$ & $2423 \pm 3616.8$ & 1993. \pm 2880.2 & $1707.6 \pm 2394.1$ & $\begin{array}{l}0.04 \\
0.06\end{array}$ & $1408.6 \pm 1252$ & $1423.8 \pm 1218$ & $1030.2 \pm 1190.4$ & 0.002 & $2322.9 \pm 3662.4$ & $2176.7 \pm 3084.3$ & $2367.7 \pm 3491.5$ & $\begin{array}{l}0.71 \\
0.65\end{array}$ \\
\hline Smoker & $103(25.6)$ & $78(19.2)$ & $21(15.8)$ & & $14(3.1)$ & $6(1.3)$ & $4(2.8)$ & & $78(16.5)$ & $91(17.2)$ & $36(19.5)$ & \\
\hline Non-smoker & $299(74.4)$ & $329(80.8)$ & $112(84.2)$ & & $439(69.6)$ & $446(98.7)$ & $139(97.2)$ & & $396(83.5)$ & $437(82.8)$ & $149(80.5)$ & \\
\hline HTN & & & & 0.001 & & & & $<0.001$ & & & & 0.57 \\
\hline Yes & $123(30.6)$ & $160(39.3)$ & $79(53.4)$ & & $87(19.2)$ & $157(34.7)$ & $74(51.7)$ & & $23(4.9)$ & $20(3.8)$ & $10(5.4)$ & \\
\hline No & $279(69.4)$ & $247(60.7)$ & $69(46.6)$ & & $366(80.8)$ & $295(65.3)$ & $69(48.3)$ & & $451(95.1)$ & $508(96.2)$ & $175(94.6)$ & \\
\hline DM & & & & 0.001 & & & & & & & & 0.20 \\
\hline Yes & $80(19.9)$ & $104(25.6)$ & $43(32.3)$ & & $63(13.9)$ & $122(27)$ & $60(42)$ & $<0.001$ & $9(1.9)$ & $13(2.5)$ & $8(4.3)$ & \\
\hline No & $322(80.1)$ & $303(74.4)$ & $90(67.7)$ & & $390(86.1)$ & $330(73)$ & $83(58)$ & & $465(98.1)$ & $515(97.5)$ & $177(95.7)$ & \\
\hline Dyslipidaemia & & & & 0.46 & & & & $<0.001$ & & & & 0.009 \\
\hline $\begin{array}{l}\text { Yes } \\
\text { No }\end{array}$ & $\begin{array}{l}322(80.1) \\
80(19.9)\end{array}$ & $\begin{array}{l}327(80.3) \\
80(19.7)\end{array}$ & $\begin{array}{l}125(84.5) \\
23(15.5)\end{array}$ & & $\begin{array}{l}357(78.8) \\
96(21.2)\end{array}$ & $\begin{array}{l}394(87.2) \\
58(12.8)\end{array}$ & $\begin{array}{c}130(90.9) \\
13(9.1)\end{array}$ & & $\begin{array}{l}248(52.3) \\
226(47.7)\end{array}$ & $\begin{array}{l}310(58.7) \\
218(41.3)\end{array}$ & $\begin{array}{l}120(64.9) \\
65(35.1)\end{array}$ & \\
\hline Obesity & & & & 0.34 & & & & & & & & $<0.001$ \\
\hline Yes & $96(23.9)$ & $103(25.3)$ & $42(31.6)$ & & & & & & $43(9.1)$ & $95(18)$ & $59(31.9)$ & \\
\hline $\begin{array}{l}\text { No } \\
\text { marital }\end{array}$ & $306(76.1)$ & $304(74.7)$ & $91(68.4)$ & & & & & & $431(90.9)$ & $433(82)$ & $126(68.1)$ & 0001 \\
\hline single & & & & & & & & & $260(54.9)$ & $254(48.1)$ & $71(38.4)$ & \\
\hline married & & & & & & & & & $214(45.1)$ & $274(51.9)$ & $114(61.6)$ & \\
\hline
\end{tabular}

Values are expressed as mean \pm SD for continuous variables and $\mathrm{n}(\%)$ for categorical Variables.

\section{Women's BMI trajectory patterns and familial cardiovascular risk factors}

As presented in Table 4, in all models, compared to women's in the normal trajectory group, those in the overweight and obesity trajectory groups had higher odds ratios for HTN, DM, and dyslipidemia $(p<0.05)$. The second model showed a higher rate of DM in men with obese spouses $(\mathrm{OR}=1.56$; $95 \% \mathrm{Cl}$ : $1.01-$ 2.39) as well as a higher rate of HTN 1.54 (95\% Cl: 1.05-2.25) even after adjusting for potential confounders. The odds ratio for DM remained significant after adjusting behavioral factors in model 3 (adjusted OR $=1.55 ; 95 \% \mathrm{Cl}: 1.00-2.44$ ). In the second and third models, the odds of men's obesity were higher in their obese spouses compared to normal weight ones, and the odds ratios were $(\mathrm{OR}=1.65 ; 95 \% \mathrm{Cl}$ : $1.09-2.51)$ and $(\mathrm{OR}=1.70 ; 95 \% \mathrm{Cl}$ : $1.10-2.62)$ respectively. In the full adjusted model, offspring of obese- and- overweight mothers were more likely to be obese compared to those whose mothers were normal weight. The odds ratios were $(\mathrm{OR}=2.39 ; 95 \% \mathrm{Cl}: 1.67-3.44)$ and $(\mathrm{OR}=4.81 ; 95 \% \mathrm{Cl}$ : $3.16-7.34)$ respectively. The corresponding values for dyslipidemia in offspring with obese mothers were 1.42 (95\% Cl: 1.01-1.98) and 1.39 (95\% Cl: 1.00-1.94) in the second and third models, respectively. No significant associations were found between the trajectory groups of mothers and their offspring's outcome, including HTN and DM. 
Table 4

Association of women's trajectories of BMI with the whole family outcomes.

\begin{tabular}{|c|c|c|c|c|c|c|c|c|c|c|}
\hline & \multicolumn{3}{|l|}{ Women } & \multicolumn{4}{|l|}{ Husband } & \multicolumn{3}{|l|}{ Offspring } \\
\hline & HTN & DM & Dyslipidaemia & HTN & DM & Dyslipidaemia & Obesity & HTN & DM & Dysli \\
\hline & $\begin{array}{l}\text { OR } \\
(95 \% \mathrm{Cl})\end{array}$ & $\begin{array}{l}\text { OR } \\
(95 \% \mathrm{Cl})\end{array}$ & OR $(95 \% \mathrm{Cl})$ & $\begin{array}{l}\text { OR } \\
(95 \% \mathrm{Cl})\end{array}$ & $\begin{array}{l}\text { OR } \\
(95 \% \mathrm{Cl})\end{array}$ & OR $(95 \% \mathrm{Cl})$ & $\begin{array}{l}\text { OR } \\
(95 \% \mathrm{Cl})\end{array}$ & $\begin{array}{l}\text { OR } \\
(95 \% \mathrm{Cl})\end{array}$ & $\begin{array}{l}\text { OR } \\
(95 \% \mathrm{Cl})\end{array}$ & OR ( \\
\hline \multicolumn{11}{|l|}{ Model 1} \\
\hline Normal & Ref. & Ref. & Ref. & Ref. & Ref. & Ref. & Ref. & Ref. & Ref. & Ref. \\
\hline Overweight & $\begin{array}{l}2.08(1.56- \\
2.76)\end{array}$ & $\begin{array}{l}2.24(1.60- \\
3.13)\end{array}$ & $\begin{array}{l}1.80(1.28- \\
2.53)\end{array}$ & $\begin{array}{l}2.13(1.60- \\
2.84)\end{array}$ & $\begin{array}{l}1.42(1.03- \\
1.95)\end{array}$ & $\begin{array}{l}0.97(0.71- \\
1.33)\end{array}$ & $\begin{array}{l}1.10(0.82- \\
1.47)\end{array}$ & $\begin{array}{l}0.98(0.57- \\
1.70)\end{array}$ & $\begin{array}{l}1.39(0.6- \\
3.26)\end{array}$ & $\begin{array}{l}1.27 ! \\
1.59\end{array}$ \\
\hline Obese & $\begin{array}{l}4.03(2.76- \\
5.89)\end{array}$ & $\begin{array}{l}4.44(2.91- \\
6.77)\end{array}$ & $\begin{array}{l}2.39(1.36- \\
4.19)\end{array}$ & $\begin{array}{l}3.58(2.45- \\
5.23)\end{array}$ & $\begin{array}{l}1.89(1.24- \\
2.86)\end{array}$ & $\begin{array}{l}0.86(0.56- \\
1.32)\end{array}$ & $\begin{array}{l}1.33(0.90- \\
1.96)\end{array}$ & $\begin{array}{l}1.14(0.55- \\
2.36)\end{array}$ & $\begin{array}{l}2.33(0.88- \\
6.13)\end{array}$ & $\begin{array}{l}1.61 ! \\
2.23 !\end{array}$ \\
\hline \multicolumn{11}{|l|}{ Model 2} \\
\hline Normal & Ref. & Ref. & Ref. & Ref. & Ref. & Ref. & Ref. & Ref. & Ref. & Ref. \\
\hline Overweight & $\begin{array}{l}1.66(1.22- \\
2.26)\end{array}$ & $\begin{array}{l}1.78(1.25- \\
2.52)\end{array}$ & $\begin{array}{l}1.58(1.11- \\
2.24)\end{array}$ & $\begin{array}{l}1.23(0.93- \\
1.62)\end{array}$ & $\begin{array}{l}1.25(0.90- \\
1.73)\end{array}$ & $\begin{array}{l}0.99(0.71- \\
1.36)\end{array}$ & $\begin{array}{l}1.24(0.91- \\
1.67)\end{array}$ & $\begin{array}{l}0.93(0.53- \\
1.63)\end{array}$ & $\begin{array}{l}1.26(0.54- \\
2.97)\end{array}$ & $\begin{array}{l}1.19 ! \\
1.50\end{array}$ \\
\hline Obese & $\begin{array}{l}3.24(2.15- \\
4.88)\end{array}$ & $\begin{array}{l}3.54(2.26- \\
5.55)\end{array}$ & $\begin{array}{l}2.04(1.15- \\
3.62)\end{array}$ & $\begin{array}{l}1.54(1.05- \\
2.25)\end{array}$ & $\begin{array}{l}1.56(1.01- \\
2.39)\end{array}$ & $\begin{array}{l}0.88(0.57- \\
1.37)\end{array}$ & $\begin{array}{l}1.65(1.09- \\
2.51)\end{array}$ & $\begin{array}{l}1.06(0.50- \\
2.21)\end{array}$ & $\begin{array}{l}2.10(0.79- \\
5.60)\end{array}$ & $\begin{array}{l}1.42 ! \\
1.98\end{array}$ \\
\hline \multicolumn{11}{|l|}{ Model 3} \\
\hline Normal & Ref. & Ref. & Ref. & Ref. & Ref. & Ref. & Ref. & Ref. & Ref. & Ref. \\
\hline Overweight & $\begin{array}{l}1.65(1.21- \\
2.24)\end{array}$ & $\begin{array}{l}1.85(1.30- \\
2.64)\end{array}$ & $\begin{array}{l}1.56(1.10- \\
2.22)\end{array}$ & $\begin{array}{l}1.21(0.91- \\
1.61)\end{array}$ & $\begin{array}{l}1.20(0.85- \\
1.68)\end{array}$ & $\begin{array}{l}1.01(0.72- \\
1.41)\end{array}$ & $\begin{array}{l}1.18(0.86- \\
1.62)\end{array}$ & $\begin{array}{l}0.92(0.52- \\
1.61)\end{array}$ & $\begin{array}{l}1.25(0.53- \\
2.94)\end{array}$ & $\begin{array}{l}1.19 ! \\
1.51 ;\end{array}$ \\
\hline Obese & $\begin{array}{l}3.19(2.11- \\
4.83)\end{array}$ & $\begin{array}{l}3.59(2.28- \\
5.64)\end{array}$ & $\begin{array}{l}1.98(1.11- \\
3.52)\end{array}$ & $\begin{array}{l}1.41(0.94- \\
2.11)\end{array}$ & $\begin{array}{l}1.55(1.00- \\
2.44)\end{array}$ & $\begin{array}{l}0.88(0.55- \\
1.41)\end{array}$ & $\begin{array}{l}1.70(1.10- \\
2.62)\end{array}$ & $\begin{array}{l}1.02(0.49- \\
2.15)\end{array}$ & $\begin{array}{l}2.09(0.78- \\
5.57)\end{array}$ & $\begin{array}{l}1.39 ! \\
1.94\end{array}$ \\
\hline
\end{tabular}

Model 1: unadjusted OR (95\% Cl)

Model 2: adjusted for age, education, employment, and marital status.

Model 3: adjusted for age, education, employment, marital status, smoking, and physical activity.

*In offspring, Model 2 and 3 are adjusted for sex in addition to the above-mentioned covariates.

\section{Discussion}

The current study aimed to evaluate the trajectory patterns of women's BMI and to determine the association between these patterns with cardiovascular risk factors at both individual and familial levels. Using six measurements of women's BMI during a 20 years follow-up period, three steady patterns of BMI were identified, including normal, overweight, and obese. Our findings indicated that women in both overweight and obese trajectories were more likely to have HTN, DM, and dyslipidemia. In addition, men with obese spouses showed a higher rate of HTN and DM. In terms of mother-offspring relationship, the odds of obesity in offspring with overweight and obese mothers were higher than those whose mothers were normal weight.

Few studies investigated developmental trajectories of BMI in particular among women. In this novel longitudinal study, we assessed trajectory patterns of BMI among Iranian women. The model classified individuals in three rising BMI patterns. The current findings were consistent with world health organization (WHO) cut-off points for BMI categorization (47). Although there is no comparable data, we compared with other studies on BMI patterns in specific life periods. A study conducted among the Chinese population aged 6-60 years identified a continuous increase of BMI in all groups of BMI (48). Some studies indicated less variability in the BMI trajectories in midlife in the total population as well as women (49-51), whereas another study reported different patterns during middle age (52). A study conducted among Australian women showed significantly three distinct BMI patterns, which was similar to our findings (53). There is only one study in Iran that determined two patterns of BMl; however, their sample included adolescents (36).

In addition, we linked the trajectory pattern of women's BMI to several cardiovascular risk factors, including high blood pressure, high blood glucose, obesity, and dyslipidemia. Our findings indicated that women in both overweight and obese trajectories were more likely to have HTN, DM, and dyslipidemia, suggesting the importance of early intervention. Previous studies have illustrated that an elevated BMI in women contributes to a high risk for DM, HTN, and high-risk HDL cholesterol, consistent with our results (54-57). In contrast, another study indicated that a rising trend of BMI was not associated with high blood pressure (58). This finding may have been due to other related factors with blood pressure, such as smoking (58). Compared with the current study, different statistical methods applied among these studies and the limited time points would also be considered. Additionally, differences among populations such as ethnicity, culture, and socioeconomic status (SES) may also explain this inconsistency (59).

In terms of spousal association, our study showed that men with obese spouses showed a higher rate of HTN and DM. There was no comparable data regarding the effect of one spouse's weight trajectories on cardio-metabolic risk factors in the other spouse. However, in line with our results, some crosssectional studies considered the spousal concordance in chronic diseases. Studies showed that husbands' health status is influenced by their wives who get 
chronic diseases (60), and changes in weight status of husbands were linked to their spouses' DM (61). Moreover, another study showed this association in the other direction in which the weight gain in wives increased the risk of type 2 diabetes in their husbands (21). The reasons may be explained by a predominant role of wives as caregivers in the families (62). Regarding lifestyles and health management, husbands may be more dependent on their spouses, which husbands with obese spouses are more likely to have chronic diseases such as obesity, HTN, and DM (63).

Regarding the association between women's BMI and CVD risk factors in their offspring, the current study reported mothers with high BMI values are predicted to have obese children, which was consistent with previous studies (64). Moreover, some cross-sectional studies in Iran and other countries reported that children with obese parents had significantly higher odds of obesity and elevated BP $(18,65,66)$. This association is more attributed to the mother-offspring relationship (67). This may be due to genetic/epigenetic factors, shared family environment, and health-related attitudes of parents in particular mothers because of their main roles in the family, which influence their children's behaviors (68). Although a number of studies reported the association between parental obesity and HTN (69), DM (70) of their offspring, a study did not find any significant association which was in line with the current results (70, 71).

This study has several strengths. This is the first report in the world, which addressed the association of BMI trajectories with cardiovascular risk factors at both individual and familial levels. The current study was conducted among the Iranian population with a relatively large sample and a long follow-up period. From an analytical point of view, LCGA was applied as a precise longitudinal method to characterize distinct BMI trajectory patterns. However, several limitations of this study need to be considered. First, the sample was limited to a metropolitan city and cannot be generalized to a rural population. Secondly, some potential predictors of cardiovascular risk factors such as genetic susceptibility and environmental conditions such as air pollution (72, 73 ) were not available in the current study.

\section{Conclusion}

In conclusion, to our knowledge, our data identified, for the first time in a relatively large community-based sample of Iranian families, three developmental trajectories of women's BMI and showed significant associations between these trajectories with obesity, dyslipidemia, HTN, and DM in their spouses and children. These findings indicated the critical role of a shared environment in determining cardiovascular risk factors. Accordingly, family-based prevention strategies should be considered for controlling cardiovascular risk factors in whole family members.

\section{List Of Abbreviations}

Cardiovascular diseases (CVDs)

diabetes mellitus (DM)

hypertension (HTN)

Socioeconomic status (SES)

Tehran Lipid and Glucose Study (TLGS)

body mass index (BMI)

Triglycerides (TGs)

High-density lipoprotein (HDL-C)

Total cholesterol (TC)

fasting plasma glucose (FPG)

2-hour post-load plasma glucose (2 hour-PLPG)

latent class growth analysis (LCGA)

systolic and diastolic blood pressure (SBP and DBP)

fasting plasma glucose (FPG)

Modifiable Activity Questionnaire (MAQ)

Bayesian information criterion (BIC)

odds of correct classification (OCC)

average posterior probability (APP)

\section{Declarations}

Ethics approval and consent to participate 
This study was approved by the research ethics committee of the Research Institute for Endocrine Sciences (RIES), Shahid Beheshti University of Medical Sciences. All procedures were in accordance with the ethical standards of the institutional and/or national research committee and with the 1964 Helsinki declaration and its later amendments or comparable ethical standards.

Informed consent was obtained from all individual participants included in the study. Prior to data collection, both children and parents were informed about the study procedure and its aims and if the child and parent agreed to participate in the study, parents were asked to sign a written consent form.

\section{Consent for publication}

Not applicable

\section{Availability of data and materials}

The datasets used and/or analyzed during the current study are available from the corresponding author on reasonable request.

\section{Competing interests}

The authors declare that they have no competing interests.

\section{Funding}

There are no funding resources for this research.

\section{Authors' contributions}

PN and PA designed the study. PN and A-ZS carried out the statistical analysis. PN, PA, and A-ZS contributed to interpretation of data. PN, A-ZS and PA drafted the manuscript. FA and PA supervised and revised the manuscript. All authors read and approved the final manuscript.

\section{Acknowledgements}

The authors are grateful to all families who participated in the current study.

\section{References}

1. Naghavi M, Abajobir AA, Abbafati C, Abbas KM, Abd-Allah F, Abera SF, et al. Global, regional, and national age-sex specific mortality for 264 causes of death, 1980-2016: a systematic analysis for the Global Burden of Disease Study 2016. The Lancet. 2017;390(10100):1151-210.

2. Kelly BB, Fuster V. Promoting cardiovascular health in the developing world: a critical challenge to achieve global health: National Academies Press; 2010.

3. Murray CJ, Vos T, Lozano R, Naghavi M, Flaxman AD, Michaud C, et al. Disability-adjusted life years (DALYs) for 291 diseases and injuries in 21 regions, 1990-2010: a systematic analysis for the Global Burden of Disease Study 2010. The Lancet. 2012;380(9859):2197-223.

4. Hatmi Z, Tahvildari S, Motlag AG, Kashani AS. Prevalence of coronary artery disease risk factors in Iran: a population based survey. BMC cardiovascular disorders. 2007;7(1):32.

5. Grundy SM, Howard B, Smith Jr S, Eckel R, Redberg R, Bonow RO. Diabetes and cardiovascular disease executive summary conference proceeding for healthcare professionals from a special writing group of the American Heart Association. Circulation. 2002;105(18):2231-9.

6. Kjeldsen SE. Hypertension and cardiovascular risk: General aspects. Pharmacological research. 2018;129:95-9.

7. Omboni S, Aristizabal D, De la Sierra A, Dolan E, Head G, Kahan T, et al. Hypertension types defined by clinic and ambulatory blood pressure in 14143 patients referred to hypertension clinics worldwide. Data from the ARTEMIS study. Journal of hypertension. 2016;34(11):2187-98.

8. Jafari-Adli S, Jouyandeh Z, Qorbani M, Soroush A, Larijani B, Hasani-Ranjbar S. Prevalence of obesity and overweight in adults and children in Iran; a systematic review. Journal of Diabetes \& Metabolic Disorders. 2014;13(1):121.

9. Saeedi P, Petersohn I, Salpea P, Malanda B, Karuranga S, Unwin N, et al. Global and regional diabetes prevalence estimates for 2019 and projections for 2030 and 2045: Results from the International Diabetes Federation Diabetes Atlas. Diabetes research and clinical practice. 2019;157:107843.

10. Mahdavi M, Parsaeian M, Mohajer B, Modirian M, Ahmadi N, Yoosefi M, et al. Insight into blood pressure targets for universal coverage of hypertension services in Iran: the 2017 ACC/AHA versus JNC 8 hypertension guidelines. BMC Public Health. 2020;20(1):1-9.

11. Majeed A, El-Sayed AA, Khoja T, Alshamsan R, Millett C, Rawaf S. Diabetes in the Middle-East and North Africa: an update. Diabetes research and clinical practice. 2014;103(2):218-22.

12. Davison KK, Birch LL. Childhood overweight: a contextual model and recommendations for future research. Obesity reviews. 2001;2(3):159-71.

13. Moore CJ, Cunningham SA. Social position, psychological stress, and obesity: a systematic review. Journal of the Academy of Nutrition and Dietetics. 2012;112(4):518-26.

14. Cutting TM, Fisher JO, Grimm-Thomas K, Birch LL. Like mother, like daughter: familial patterns of overweight are mediated by mothers' dietary disinhibition. The American journal of clinical nutrition. 1999;69(4):608-13.

15. Pike KM, Rodin J. Mothers, daughters, and disordered eating. Journal of abnormal psychology. 1991;100(2):198.

16. Vik KL, Romundstad P, Carslake D, Davey Smith G, Nilsen TI. Comparison of father-offspring and mother-offspring associations of cardiovascular risk factors: family linkage within the population-based HUNT Study, Norway. International journal of epidemiology. 2014;43(3):760-71. 
17. Danielzik S, Langnäse K, Mast M, Spethmann C, Müller MJ. Impact of parental BMI on the manifestation of overweight 5-7 year old children. European journal of nutrition. 2002;41(3):132-8.

18. Gibson LY, Byrne SM, Davis EA, Blair E, Jacoby P, Zubrick SR. The role of family and maternal factors in childhood obesity. Medical journal of Australia. 2007;186(11):591-5.

19. Drake AJ, Reynolds RM. Focus on obesity: Impact of maternal obesity on offspring obesity and cardiometabolic disease risk. Reproduction. 2010;140:387-98.

20. Lee C-Y, Lin W-T, Tsai S, Hung Y-C, Wu P-W, Yang Y-C, et al. Association of parental overweight and cardiometabolic diseases and pediatric adiposity and lifestyle factors with cardiovascular risk factor clustering in adolescents. Nutrients. 2016;8(9):567.

21. Nielsen J, Hulman A, Witte DR. Spousal cardiometabolic risk factors and incidence of type 2 diabetes: a prospective analysis from the English Longitudinal Study of Ageing. Diabetologia. 2018;61(7):1572-80.

22. Meyler D, Stimpson JP, Peek MK. Health concordance within couples: a systematic review. Social science \& medicine. 2007;64(11):2297-310.

23. Peek MK, Markides KS. Blood pressure concordance in older married Mexican-American couples. Journal of the American Geriatrics Society. 2003;51(11):1655-9.

24. Wang Z, Ji W, Song Y, Li J, Shen Y, Zheng H, et al. Spousal concordance for hypertension: A meta-analysis of observational studies. The Journal of Clinical Hypertension. 2017;19(11):1088-95.

25. Di Castelnuovo A, Quacquaruccio G, Jozef A, Cappuccio FP, de Lorgeril M, Dirckx C, et al. Cardiovascular risk factors and global risk of fatal cardiovascular disease are positively correlated between partners of 802 married couples from different European countries. Thrombosis and haemostasis. 2007;98(09):648-55.

26. Di Castelnuovo A, Quacquaruccio G, Donati MB, De Gaetano G, lacoviello L. Spousal concordance for major coronary risk factors: a systematic review and meta-analysis. American journal of epidemiology. 2009;169(1):1-8.

27. Macken LC, Yates B, Blancher S. Concordance of risk factors in female spouses of male patients with coronary heart disease. Journal of Cardiopulmonary Rehabilitation and Prevention. 2000;20(6):361-8.

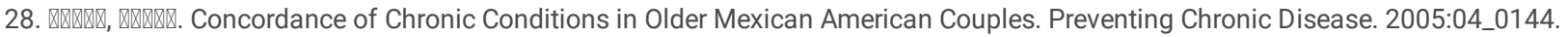

29. Khan A, Lasker SS, Chowdhury TA. Are spouses of patients with type 2 diabetes at increased risk of developing diabetes? Diabetes care. 2003;26(3):7102.

30. Ramezankhani A, Guity K, Azizi F, Hadaegh F. Sex differences in the association between spousal metabolic risk factors with incidence of type 2 diabetes: a longitudinal study of the Iranian population. Biology of sex differences. 2019;10(1):41.

31. Ramezankhani A, Guity K, Azizi F, Hadaegh F. Spousal metabolic risk factors and incident hypertension: A longitudinal cohort study in Iran. The Journal of Clinical Hypertension. 2020;22(1):95-102.

32. Babu GC, Shantharajah S. Optimal body mass index cutoff point for cardiovascular disease and high blood pressure. Neural computing and applications. 2019;31(5):1585-94.

33. Pryor LE, Tremblay RE, Boivin M, Touchette E, Dubois L, Genolini C, et al. Developmental trajectories of body mass index in early childhood and their risk factors: an 8-year longitudinal study. Archives of pediatrics \& adolescent medicine. 2011;165(10):906-12.

34. Barker DJ, Osmond C, Forsén TJ, Kajantie E, Eriksson JG. Trajectories of growth among children who have coronary events as adults. New England Journal of Medicine. 2005;353(17):1802-9.

35. Lacey R, Sacker A, Bell S, Kumari M, Worts D, McDonough P, et al. Work-family life courses and BMI trajectories in three British birth cohorts. International Journal of Obesity. 2017;41(2):332-9.

36. Ahanchi NS, Ramezankhani A, Munthali RJ, Asgari S, Azizi F, Hadaegh F. Body mass index trajectories from adolescent to young adult for incident high blood pressure and high plasma glucose. PloS one. 2019;14(5):e0213828.

37. VanWagner LB, Khan SS, Ning H, Siddique J, Lewis CE, Carr JJ, et al. Body mass index trajectories in young adulthood predict non-alcoholic fatty liver disease in middle age: the CARDIA cohort study. Liver International. 2018;38(4):706-14.

38. Hao G, Wang X, Treiber FA, Harshfield G, Kapuku G, Su S. Body mass index trajectories in childhood is predictive of cardiovascular risk: results from the 23-year longitudinal Georgia Stress and Heart study. International Journal of Obesity. 2018;42(4):923-5.

39. Azizi F, Ghanbarian A, Momenan AA, Hadaegh F, Mirmiran P, Hedayati M, et al. Prevention of non-communicable disease in a population in nutrition transition: Tehran Lipid and Glucose Study phase II. Trials. 2009;10(1):5.

40. Momenan AA, Delshad M, Sarbazi N, REZAEI GN, Ghanbarian A, AZIZI F. Reliability and validity of the Modifiable Activity Questionnaire (MAQ) in an Iranian urban adult population. 2012.

41. Chobanian AV, Bakris GL, Black HR, Cushman WC, Green LA, Izzo Jr JL, et al. The seventh report of the joint national committee on prevention, detection, evaluation, and treatment of high blood pressure: the JNC 7 report. Jama. 2003;289(19):2560-71.

42. Association AD. 2. Classification and diagnosis of diabetes: standards of medical care in diabetes-2019. Diabetes care. 2019;42(Supplement 1):S13S28.

43. Expert Panel on Detection E. Executive summary of the third report of the National Cholesterol Education Program (NCEP) expert panel on detection, evaluation, and treatment of high blood cholesterol in adults (Adult Treatment Panel III). Jama. 2001;285(19):2486.

44. Cole TJ, Bellizzi MC, Flegal KM, Dietz WH. Establishing a standard definition for child overweight and obesity worldwide: international survey. Bmj. 2000;320(7244):1240.

Page 9/11 
45. Nagin DS, Jones BL, Passos VL, Tremblay RE. Group-based multi-trajectory modeling. Statistical Methods in Medical Research. 2018;27(7):2015-23. 46. Nagin DS, NAGIN D. Group-based modeling of development: Harvard University Press; 2005.

47. 2017. GDoBMIhwacihAS.

48. Islam MT, Möller J, Zhou X, Liang Y. Life-course trajectories of body mass index and subsequent cardiovascular risk among Chinese population. PloS one. 2019;14(10):e0223778.

49. Wang M, Yi Y, Roebothan B, Colbourne J, Maddalena V, Sun G, et al. Trajectories of body mass index among Canadian seniors and associated mortality risk. BMC Public Health. 2017;17(1):929.

50. Wang M, Yi Y, Roebothan B, Colbourne J, Maddalena V, Wang PP, et al. Body mass index trajectories among middle-aged and elderly Canadians and associated health outcomes. Journal of environmental and public health. 2016;2016.

51. Botoseneanu A, Liang J. Latent heterogeneity in long-term trajectories of body mass index in older adults. Journal of aging and health. 2013;25(2):34263.

52. Buscot M-J, Thomson RJ, Juonala M, Sabin MA, Burgner DP, Lehtimäki T, et al. Distinct child-to-adult body mass index trajectories are associated with different levels of adult cardiometabolic risk. European heart journal. 2018;39(24):2263-70.

53. Kakoly NS, Earnest A, Moran LJ, Teede HJ, Joham AE. Group-based developmental BMI trajectories, polycystic ovary syndrome, and gestational diabetes: a community-based longitudinal study. BMC medicine. 2017;15(1):195.

54. Buscot M-J, Thomson RJ, Juonala M, Sabin MA, Burgner DP, Lehtimäki T, et al. BMI trajectories associated with resolution of elevated youth BMI and incident adult obesity. Pediatrics. 2018;141(1):e20172003.

55. Yuan Y, Chu C, Zheng W-L, Ma Q, Hu J-W, Wang Y, et al. Body Mass Index Trajectories in Early Life Is Predictive of Cardiometabolic Risk. The Journal of Pediatrics. 2020.

56. Zheng Y, Manson JE, Yuan C, Liang MH, Grodstein F, Stampfer MJ, et al. Associations of weight gain from early to middle adulthood with major health outcomes later in life. Jama. 2017;318(3):255-69.

57. Börnhorst C, Tilling K, Russo P, Kourides Y, Michels N, Molnár D, et al. Associations between early body mass index trajectories and later metabolic risk factors in European children: the IDEFICS study. European journal of epidemiology. 2016;31(5):513-25.

58. Li L, Hardy R, Kuh D, Power C. Life-course body mass index trajectories and blood pressure in mid life in two British birth cohorts: stronger associations in the later-born generation. International journal of epidemiology. 2015;44(3):1018-26.

59. Haines J, Rifas-Shiman SL, Horton NJ, Kleinman K, Bauer KW, Davison KK, et al. Family functioning and quality of parent-adolescent relationship: crosssectional associations with adolescent weight-related behaviors and weight status. International Journal of Behavioral Nutrition and Physical Activity. 2016;13(1):68.

60. Valle G, Weeks JA, Taylor MG, Eberstein IW. Mental and physical health consequences of spousal health shocks among older adults. Journal of aging and health. 2013;25(7):1121-42.

61. Silverman-Retana O, Hulman A, Simmons RK, Nielsen J, Witte DR. Trajectories of obesity by spousal diabetes status in the English Longitudinal Study of Ageing. Diabetic Medicine. 2019;36(1):105-9.

62. Maccoby EE. Gender and group process: A developmental perspective. Current directions in psychological science. 2002;11(2):54-8.

63. Liao J, Zhang J, Xie J, Gu J. Gender Specificity of Spousal Concordance in the Development of Chronic Disease Among Middle-Aged and Older Chinese Couples: A Prospective Dyadic Analysis. 2020.

64. Chivers P, Parker H, Bulsara M, Beilin L, Hands B. Parental and early childhood influences on adolescent obesity: a longitudinal study. Early Child Development and Care. 2012;182(8):1071-87.

65. Hernández-Valero MA, Wilkinson AV, Forman MR, Etzel CJ, Cao Y, Bárcenas $\mathrm{CH}$, et al. Maternal BMI and country of birth as indicators of childhood obesity in children of Mexican origin. Obesity. 2007;15(10):2512-9.

66. Ejtahed H-S, Heshmat R, Motlagh ME, Hasani-Ranjbar S, Ziaodini H, Taheri M, et al. Association of parental obesity with cardiometabolic risk factors in their children: The CASPIAN-V study. PloS one. 2018;13(4):e0193978.

67. Muthuri SK, Onywera VO, Tremblay MS, Broyles ST, Chaput J-P, Fogelholm M, et al. Relationships between parental education and overweight with childhood overweight and physical activity in 9-11 year old children: Results from a 12-country study. PloS one. 2016;11(8):e0147746.

68. Ventura AK, Birch LL. Does parenting affect children's eating and weight status? International Journal of Behavioral Nutrition and Physical Activity. 2008;5(1):1-12.

69. Fraser A, Tilling K, Macdonald-Wallis C, Sattar N, Brion M-J, Benfield L, et al. Association of maternal weight gain in pregnancy with offspring obesity and metabolic and vascular traits in childhood. Circulation. 2010;121(23):2557.

70. Veena SR, Krishnaveni GV, Karat SC, Osmond C, Fall CH. Testing the fetal overnutrition hypothesis; the relationship of maternal and paternal adiposity to adiposity, insulin resistance and cardiovascular risk factors in Indian children. Public health nutrition. 2013;16(9):1656-66.

71. Labayen I, Ruiz JR, Ortega FB, Loit H-M, Harro J, Veidebaum T, et al. Intergenerational cardiovascular disease risk factors involve both maternal and paternal BMI. Diabetes care. 2010;33(4):894-900.

72. Sun D, Liu J, Xiao L, Liu Y, Wang Z, Li C, et al. Recent development of risk-prediction models for incident hypertension: An updated systematic review. PloS one. 2017;12(10):e0187240.

73. Wu L, Sun D, He Y. Fruit and vegetables consumption and incident hypertension: dose-response meta-analysis of prospective cohort studies. Journal of human hypertension. 2016;30(10):573-80.

Page $10 / 11$ 
Figures

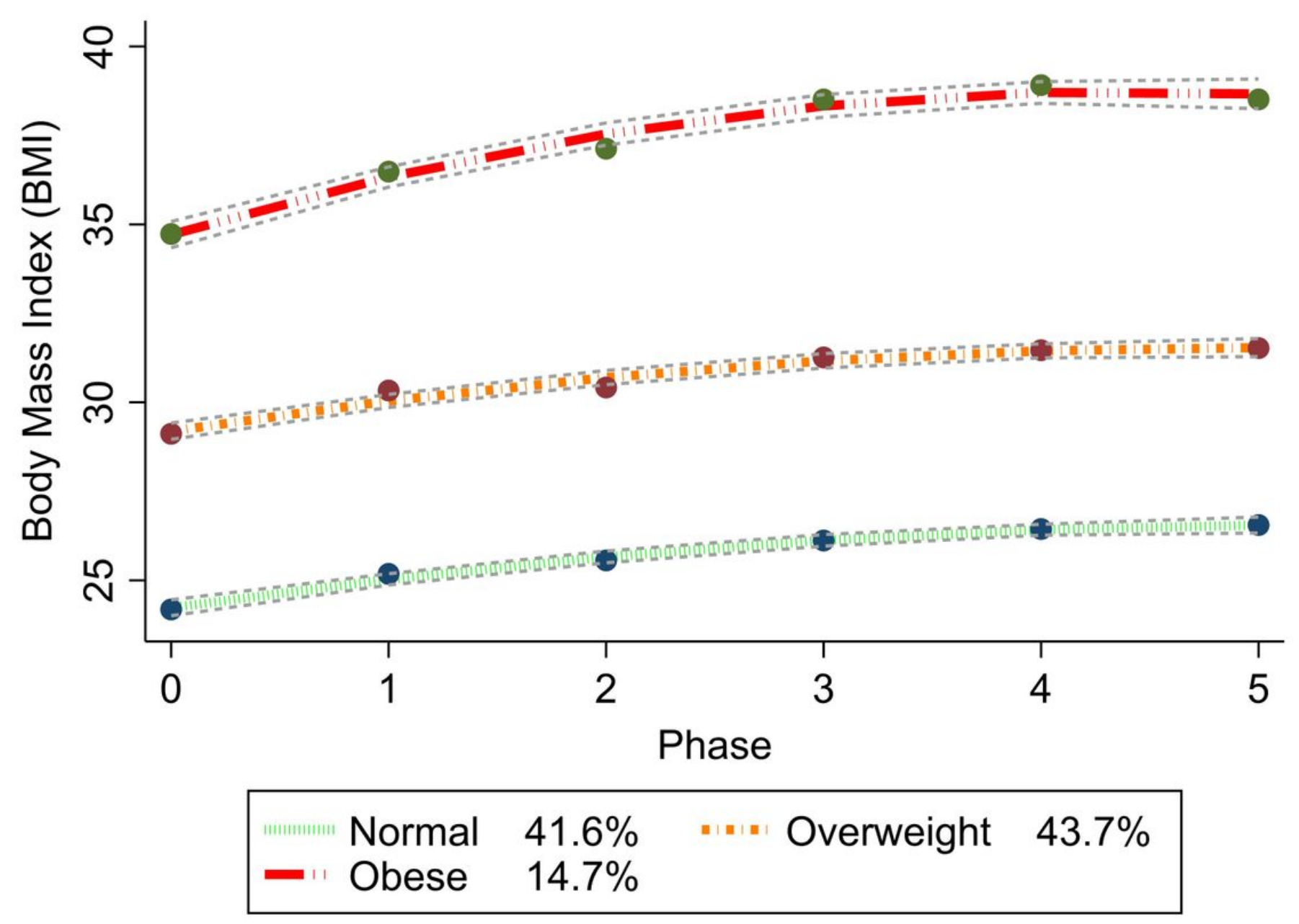

Figure 1

Women's BMI trajectories. Dashed lines indicate the $95 \%$ confidence intervals. 